\title{
Longitudinal Evaluation Nocturnal Sleep Behaviors of Healthy and Well Developed Children Born Prematurely
}

\author{
Yoko Asaka1, Satoshi Takada ${ }^{2}$ \\ ${ }^{1}$ Faculty of Health Sciences, Hokkaido University, Sapporo, Japan \\ ${ }^{2}$ Kobe University Graduate School of Health Sciences, Kobe, Japan \\ Email: y_asaka@hs.hokudai.ac.jp
}

Received 28 January 2016; accepted 4 February 2016; published 9 March 2016

Copyright (C) 2016 by authors and Scientific Research Publishing Inc.

This work is licensed under the Creative Commons Attribution International License (CC BY). http://creativecommons.org/licenses/by/4.0/

c) (i) Open Access

\begin{abstract}
The aim of the study is to examine nocturnal sleep measures of healthy and well developed preterm infants by birth weight when they were averaged 15 corrected months and became elementary school children. Sleep measures were collected by actigraphs (Micro-mini RC, Ambulatory Monitoring Inc., New York, USA). Nocturnal sleep quality of children born as extremely low birth weight (ELBW) was significantly inferior with that of children born as very low birth weight (VLBW) at 15 corrected months [number of night waking: 6.0 (4.5 - 8.0), ELBW 8.5 (7.0 - 10.3) (Z = 2.47, p < 0.01), wake after sleep onset: VLBW 99.0 (73.0 - 115.0) $\mathrm{min}$, ELBW 146.5 (94.8 - 171.3) $\min (\mathrm{Z}=2.89, \mathrm{p}<0.01)]$. However, these measures did not show any significant differences by birth weight at second data collection period [number of night waking: VLBW $0.0(0.0-1.0)$, ELBW $1.0(0.0$ - 2.5) ( $\mathrm{Z}=-0.62$, n.s.), wake after sleep onset: VLBW 16.0 (8.0 - 27.0) min, ELBW 15.0 (6.0 32.5) $\min (Z=0.00$, n.s. $)]$. It was assumed that nocturnal measures were affected by the birth weight at the age of 15 corrected months in ELBW infants, but could not predict the future sleep problems at this point.
\end{abstract}

\section{Keywords}

Nocturnal Sleep, Longitudinal Evaluation, Extremely Low Birth Weight Infant, Actigraph

\section{Introduction}

Improvement of prognosis among preterm infants in neonatal medical treatment has advanced dramatically [1]. More than $80 \%$ of extremely low birth weight infants are surviving every year after the year 2000 in Japan. It is 
widely known that these preterm infants have a greater risk of major complications, such as severe intraventricular haemorrhage, which may cause severe neurological problems in their future [2]. Also an association between preterm infants and developmental disorders has been of current interest in Japan. Recently, it was reported that the incidence of developmental disorders among extremely low birth weight ELBW infants were 25\% in attention-deficit/hyper-activity disorder (ADHD), 20\% in learning disorder and 7\% in pervasive developmental disorder in Japan [3]. These results were 2 - 10 times higher than the results which were reported in 2003. Especially, the ADHD was about twice as high in preterm infants who were born between 22 - 28 gestational weeks as in term infants [4]. Early detection of developmental disorders is the key in socializing in their community. Thus, preterm infants are needed to be routinely assessed with their development, and establishing strategy of early detection is one of the urgent issues in Japan.

We previously reported that preterm infants slept less and had a larger percentage of less restful sleep during nighttime at around 12 corrected months [5]. We also have been considering the possibility of finding any unique sleep characteristics which could detect ADHD early in this population since a link between sleep disturbances and ADHD has been pointed out [6]. To clarify this question, accumulating longitudinal sleep measures of preterm infants is important for deeper understanding of sleep development among preterm infants. Thus, the aim of this study is to examine nocturnal sleep measures of healthy and well developed preterm infants when they were averaged 15 corrected months (first data collection) and when they became an elementary school student (second data collection).

\section{Methods}

\subsection{Subjects}

The subjects were children born in preterm (average gestational weeks of $27.8 \pm 2.6$ and average weights of $974.0 \pm 247.3 \mathrm{~g}$, respectively). They took part in the first data collection at an age of around 15 corrected months. These subjects met all criteria at the first data collection period [5]. Inclusion criteria were 1) no neurological or developmental problems and 2) birth weight of less than $1500 \mathrm{~g}$ and born before 32 gestational weeks. Exclusion criteria were 1) severe illness or congenital abnormality and 2) use of infant medication with sedative effects. All of them were first graders in elementary school and has adapted to their school life at the second data collection period. They received developmental assessment regularly from neonatologists and psychologists in follow-up outpatient clinic until they entered elementary school.

\subsection{Procedures}

Basically, data collection was done in a similar way for both data collection periods, the methods of first data collection are described elsewhere [5]. Children's sleep measures were obtained through actigraphs (Micro-mini RC, Ambulatory Monitoring Inc., New York, United States). The actigraph is a wristwatch-like device (Figure $1(a)$ ), which is consists of a piezoelectric sensor sensitive to accelerations above $0.01 \mathrm{~g}$ per second and has an internal memory. Each detected activity is counted, digitized, and stored in the memory. The actigraph collected data using a zero-crossing mode, one-minute epochs, and filter setting mode 18. Mothers were instructed to keep the actigraph on the children's ankle in the first data collection period, and children's non-dominant wrist in the second data collection period (Figure 1(b)), continuously for seven days. The mothers were also asked to com-

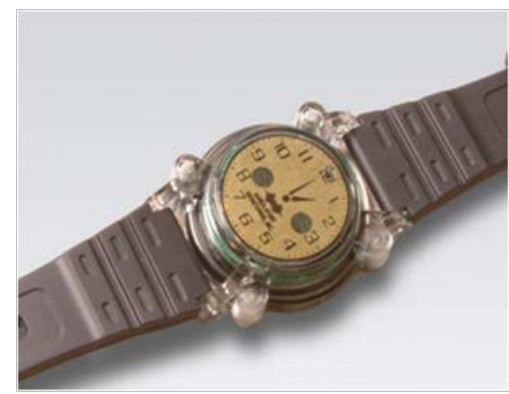

(a)

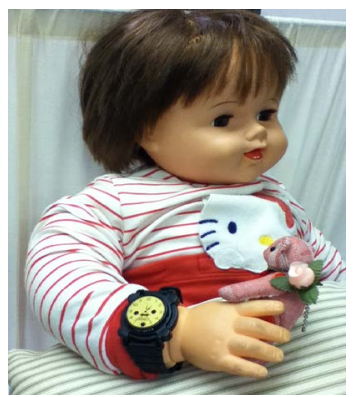

(b)

Figure 1.The actigraph. 
plete the daily sleep logs documenting the nocturnal sleep patterns of the children. They were asked to write the sleep state of the children every 30 minutes in the sleep logs. The sleep logs included information about bedtime, waking time and the time when the device was taken off. Also, they were asked to complete the questionnaire to inquire about socio-demographic information and about children's sleep.

The subjects were recruited from parenting classes which were held by Kobe General Children's Center, Japan at the first data collection. Then, the researchers made contact with 15 mothers who participated in the first data collection by phone or postcards. Personal interviews were arranged with the mothers who indicated a wish to participate in the second study. The mothers were informed of the procedures for this study during the interview. We asked the mothers to explain the study procedures to their children and confirm the children's agreement. Written informed consent was obtained from each mother before the commencement of the study. Data collection was done from February 2007 through May 2008 and March 2013 through November 2013. Study procedures were approved (approved number 12 - 65) by the Medical Ethics Committee of Hokkaido University, Japan.

\subsection{Data Analysis}

The recorded activity data was downloaded to a personal computer (Windows-type) using the automatic actigraph interface unit. Activity data of weekdays were analyzed using the actigraphic scoring analysis software program, action-w2. "Sadeh" was chosen as the algorithm for all subjects in this study [7]. Sleep measures included sleep onset time, sleep offset time, nocturnal sleep duration, number of night-waking (of more than five minutes), the longest sleep episode, the longest wake episode, WASO (wake after sleep onset: wake minutes during nocturnal sleeping), sleep efficiency defined as the percentage of the sleep period spent asleep: which was calculated as following formula ([Sleep time/Sleep period] * 100) and activity measures including mean activity score and ACTX (Activity Index: percentage minutes with more than 0 activity score).Sleep measures estimated at two data collection periods were respectively examined by birth weight. Statistical analysis was performed using a nonparametric U test from Mann and Whitney. Statistical procedures were carried out using SPSS Ver17.0 for Windows.

\section{Results}

Eight mothers out of 15 mothers were reached by phone or postcards. Two mothers declined to participate in the second data collection because of taking care of their younger children. The subjects were 6 neurologically healthy children with their age ranging from 78 to 88 months old. All of them slept with their mothers. Three were born as an ELBW infant and others were born as a very low birth weight (VLBW) infant. Also, 2 children (No.1 and No.4 in Table 1) were evaluated as intrauterine growth. Two children's bodyweight (No.1 and No. 5 in Table 1) was below -2SD, yet a head circumstance was in normal range of Japanese growth curve at the first data collection period. None of them were evaluated as under nutrition in the second data collection period. None of their mothers were concerned about their children's sleep problems and reported that their children were not pointed out of any maladjusted behaviors from their elementary schools.

We analyzed only the nocturnal sleep behaviors in this research because two children wore the actigraphs only during the nighttime. As shown in Table 2, nocturnal sleep measures of children born as ELBW infants were significantly different from those of children born as VLBW infants at average of 15 corrected months. However, sleep measures did not show any significant differences by birth weight in the second data collection period.

\section{Discussion}

The actigraph is capable to measure activity data continuously and estimate sleep measures through the use of algorithms. Although specificity to detect wake status varies with studies and is relatively low, sensitivity to detect sleep status is highly correlated with polysomnography or direct observation method [8]. Thus, it could be possible to assess the development of nocturnal sleep behaviors from activity data, even though polysomnography is necessary to diagnose sleep quality. Moreover, activity counts could be valuable information to examine sleep behaviors of children born prematurely, since association between sleep disturbances, such as moving about excessively during sleep and ADHD, has been pointed out [9].

This research provided the longitudinal nocturnal sleep behaviors of healthy and well developed children born 
Table 1. Background and physical measurement of the subjects.

\begin{tabular}{|c|c|c|c|c|c|c|c|c|c|c|c|c|c|c|}
\hline \multirow[b]{2}{*}{ No. } & \multirow[b]{2}{*}{ Sex } & \multirow[b]{2}{*}{$\begin{array}{l}\mathrm{Ap}^{\mathrm{a}} \\
1^{\prime}\end{array}$} & \multirow[b]{2}{*}{$\begin{array}{l}\mathrm{Ap}^{\mathrm{b}} \\
5^{\prime}\end{array}$} & \multicolumn{4}{|c|}{ At the time of birth } & \multicolumn{4}{|c|}{ First data collection } & \multicolumn{3}{|c|}{ Second data collection } \\
\hline & & & & $\begin{array}{c}\text { Week of } \\
\text { birth }\end{array}$ & $\begin{array}{l}\text { Weight } \\
\text { (g) }\end{array}$ & $\begin{array}{l}\text { Height } \\
(\mathrm{cm})\end{array}$ & $\begin{array}{l}\mathrm{HC}^{\mathrm{c}} \\
(\mathrm{cm})\end{array}$ & $\begin{array}{l}\text { Age of } \\
\text { months }\end{array}$ & $\begin{array}{l}\text { Weight } \\
\text { (g) }\end{array}$ & $\begin{array}{l}\text { Height } \\
\text { (cm) }\end{array}$ & $\begin{array}{l}\mathrm{H} \mathrm{C}^{\mathrm{c}} \\
(\mathrm{cm})\end{array}$ & $\begin{array}{l}\text { Age of } \\
\text { months }\end{array}$ & $\begin{array}{l}\text { Weight } \\
\text { (g) }\end{array}$ & $\begin{array}{l}\text { Height } \\
(\mathrm{cm})\end{array}$ \\
\hline 1 & M & 8 & 9 & 32 & 1174 & 37.5 & 26.5 & 15 & 7405 & 71.7 & 45.5 & 85 & 19,300 & 116.0 \\
\hline 2 & M & 5 & 7 & 27 & 1084 & 35.0 & 24.4 & 14 & 8013 & 69.2 & 44.5 & 78 & 20,500 & 114.8 \\
\hline 3 & $\mathrm{~F}$ & 1 & Intubation & 30 & 1270 & 44.0 & 33.0 & 15 & 8595 & 74.2 & 47.0 & 86 & 17,000 & 114.0 \\
\hline 4 & M & 8 & 8 & 27 & 662 & 29.6 & 23.8 & 14 & 8590 & 74.5 & 45.8 & 85 & 18,500 & 110.5 \\
\hline 5 & $\mathrm{~F}$ & $\mathrm{NA}^{\mathrm{d}}$ & $N^{d}$ & 25 & 714 & 31.0 & 21.0 & 16 & 8000 & 72.0 & 44.8 & 88 & 20,000 & 112.0 \\
\hline 6 & M & 5 & 7 & 26 & 940 & 31.0 & 24.0 & 15 & 9055 & 75.3 & 47.0 & 78 & 18,500 & 110.5 \\
\hline
\end{tabular}

a. AP1': Apgar score at 1 minute, b. AP5': Apgar score at 5 minutes, c: HC: Head circumstance, d. NA: No answer.

Table 2. Nocturnal sleep measure by birth weight (median, interquartile range).

\begin{tabular}{|c|c|c|c|c|c|c|}
\hline & \multicolumn{3}{|c|}{ First data collection } & \multicolumn{3}{|c|}{ Second data collection } \\
\hline & VLBW & ELBW & $\mathrm{Z}$ & VLBW & ELBW & $\mathrm{Z}$ \\
\hline Sleep onset time, PM & $\begin{array}{c}22: 06 \\
(21: 13-22: 45)\end{array}$ & $\begin{array}{c}21: 09 \\
(20: 28-21: 59)\end{array}$ & $2.61^{* *}$ & $\begin{array}{c}21: 41 \\
(20: 33-22: 13)\end{array}$ & $\begin{array}{c}21: 33 \\
(21: 23-22: 23)\end{array}$ & -0.63 \\
\hline Sleep offset time, AM & $\begin{array}{c}6: 21 \\
(5: 39-7: 13)\end{array}$ & $\begin{array}{c}7: 05 \\
(6: 19-4: 40)\end{array}$ & $2.02^{*}$ & $\begin{array}{c}6: 57 \\
(6: 09-7: 10)\end{array}$ & $\begin{array}{c}6: 11 \\
(5: 53-7: 06)\end{array}$ & -0.98 \\
\hline $\begin{array}{l}\text { Nocturnal sleep duration } \\
\text { (min) }\end{array}$ & $\begin{array}{c}394.0 \\
(371-431)\end{array}$ & $\begin{array}{c}436.5 \\
(379-475)\end{array}$ & -1.52 & $\begin{array}{c}554.0 \\
(512-580)\end{array}$ & $\begin{array}{c}488.0 \\
(448-565)\end{array}$ & -0.08 \\
\hline Sleep efficiency (\%) & $\begin{array}{c}81.2 \\
(76.3-86.1)\end{array}$ & $\begin{array}{c}74.4 \\
(69.2-83.1)\end{array}$ & $2.10^{*}$ & $\begin{array}{c}97.2 \\
(95.3-98.6)\end{array}$ & $\begin{array}{c}97.0 \\
(93.9-98.7)\end{array}$ & -0.21 \\
\hline WASO (\%) & $\begin{array}{c}99.0 \\
(73.0-115.0)\end{array}$ & $\begin{array}{c}146.5 \\
(94.8-171.3)\end{array}$ & $2.89^{* *}$ & $\begin{array}{c}16.0 \\
(8.0-27.0)\end{array}$ & $\begin{array}{c}15.0 \\
(6.0-32.5)\end{array}$ & 0.00 \\
\hline Number of night-waking & $\begin{array}{c}6.0 \\
(4.5-8.0)\end{array}$ & $\begin{array}{c}8.5 \\
(7.0-10.3)\end{array}$ & $2.47^{* *}$ & $\begin{array}{c}0.0 \\
(0.0-1.0)\end{array}$ & $\begin{array}{c}1.0 \\
(0.0-2.5)\end{array}$ & -0.62 \\
\hline Longest wake episode (min) & $\begin{array}{c}23.0 \\
(19.5-27.5)\end{array}$ & $\begin{array}{c}36.5 \\
(21.0-42.3)\end{array}$ & $2.05^{*}$ & $\begin{array}{c}4.0 \\
(3.0-7.0)\end{array}$ & $\begin{array}{c}5.0 \\
(2.0-10.0)\end{array}$ & -0.31 \\
\hline Longest sleep episode (min) & $\begin{array}{c}100.0 \\
(66.0-133.0)\end{array}$ & $\begin{array}{c}92.5 \\
(64.0-124.5)\end{array}$ & -0.47 & $\begin{array}{c}166.0 \\
(108.0-222.0)\end{array}$ & $\begin{array}{c}181.0 \\
(125.5-198.5)\end{array}$ & -0.10 \\
\hline $\begin{array}{l}\text { Mean activity score } \\
\text { (count } / \mathrm{min})\end{array}$ & $\begin{array}{c}20.3 \\
(15.7-24.9)\end{array}$ & $\begin{array}{c}23.4 \\
(17.7-30.4)\end{array}$ & -1.47 & $\begin{array}{c}9.7 \\
(8.9-12.0)\end{array}$ & $\begin{array}{c}10.3 \\
(8.8-13.1)\end{array}$ & -0.04 \\
\hline $\operatorname{ACTX~(\% )~}$ & $\begin{array}{c}63.0 \\
(56.5-69.0)\end{array}$ & $\begin{array}{c}56.5 \\
(46.5-58.3)\end{array}$ & $2.75^{* *}$ & $\begin{array}{c}41.4 \\
(34.7-43.4)\end{array}$ & $\begin{array}{c}38.9 \\
(33.1-42.6)\end{array}$ & -0.56 \\
\hline
\end{tabular}

${ }^{* *} \mathrm{P}<0.01 ;{ }^{*} \mathrm{P}<0.05$

prematurely. Although the number of subjects was small, it was important to accumulate the sleep measures of preterm infants, which were assumed to be high risk group of developmental disorders, to understand their typical sleep development. Some nocturnal sleep measures of children born as ELBW infants showed inferior sleep quality than those of children born as VLBW infants at averaged 15 corrected months. However, sleep measures did not differ by birth weight in the second data collection. According to the previous studies [10]-[12], average sleep measures of elementary school children in this research were not different from the healthy children of comparable ages. Thus, the results showed that sleep measures of preterm infants were developed from infancy through childhood regardless of their birth weight. It could be possible to think nocturnal measures were affected by the birth weight at the age of around 15 corrected months in preterm infants, but could not predict future sleep problems at this point. Also, none of the children maintained high level of physical activity, according to mean activity score and Activity Index (ACTX).

It was reported that under nutrition affected long-term physical growth in preterm infants [13]. Also, a clear relationship exists between under nutrition and poor development [14]. The physical measurements of the subjects at the second data collection did not suggest under nutrition in this research. Even though two intrauterine growth infants were included in this study, sleep developed normally among children born as ELBW and VLBW, as 
long as they were not evaluated as under nutrition when they were reaching the first grade of elementary school.

This study showed valuable longitudinal sleep data of children born prematurely. However, it is not possible to generalize the results due to small number of subjects. To identify unique sleep characteristics which could detect ADHD in preterm infants, it is necessary to perform a longitudinal study including the subjects diagnosed with ADHD.

\section{Acknowledgements}

This study was supported by a research grant from the Ministry of Education, Culture, Sports, Science and Technology (C-23593353), Japan. The authors declare that they have no conflict of interest.

\section{References}

[1] Kusuda, S., Fujimura, M., Sakuma, I., Aotani, H., Kabe, K., Itani, Y., et al. (2013) Morbidity and Mortality of Infants with Very Low Birth Weight in Japan: Center Variation. Pediatrics, 118, e1130-e1138. http://dx.doi.org/10.1542/peds.2005-2724

[2] EXPRESS Group (2010) Incidence of and Risk Factors for Neonatal Morbidity after Active Perinatal Care: Extremely Preterm Infants Study in Sweden (EXPRESS). Acta Paediatrica, 99, 978-992. http://dx.doi.org/10.1111/j.1651-2227.2010.01846.x

[3] Kanazawa, T., Yasuda, J., Kitamura, M., et al. (2007) Neurological Prognosis and Evaluation of Extremely-Low Birth Weight. Perinatal Medicine, 37, 485-487. (In Japanese)

[4] Lindström, K., Lindblad, F. and Hjern, A. (2011) Preterm Birth and Attention-Deficit/Hyperactivity Disorder in Schoolchildren. Pediatrics, 127, 858-865. http://dx.doi.org/10.1542/peds.2010-1279

[5] Asaka, Y. and Takada, S. (2010) Activity-Based Assessment of the Sleep Behaviors of VLBW Preterm Infants and Full-Term Infants at Around 12 Months of Age. Brain Development, 32, 150-155. http://dx.doi.org/10.1016/j.braindev.2008.12.006

[6] Owens, J., Gruber, R., Brown, T., Corkum, P., Cortese, S., O’Brien, L., et al. (2013) Future Research Directions in Sleep and ADHD: Report of a Consensus Working Group. Journal of Attention Disorders, 17, 550-564. http://dx.doi.org/10.1177/1087054712457992

[7] Sadeh, A., Sharkey, K.M. and Carskadon, M. (1994) Activity-Based Sleep-Wake Identification: An Empirical Test of Methodological Issues. Sleep, 17, 201-207.

[8] Meltzer, L.J., Montgomery-Downs, H.E., Insana, S.P. and Walsh, C.M. (2012) Use of Actigraphy for Assessment in Pediatric Sleep Research. Sleep Medicine Reviews, 16, 463-475. http://dx.doi.org/10.1016/j.smrv.2011.10.002

[9] Konofal, K., Lecendreux, M. and Cortese, S. (2010) Sleep and ADHD. Sleep Medicine, 11, 652-658. http://dx.doi.org/10.1016/j.sleep.2010.02.012

[10] Ancoli-Israel, S., Cole, R., Alessi, C., Chambers, M., Moorcroft, W. and Pollak, C.P. (2003) The Role of Actigraphy in the Study of Sleep and Circadian Rhythms. Sleep, 26, 342-392.

[11] Acebo, C., Sadeh, A., Seifer, R., Tzischinsky, O., Hafer, A. and Carskadon, M.A. (2005) Sleep/Wake Patterns Derived from Activity Monitoring and Maternal Report for Healthy 1- to 5-Year-Old Children. Sleep, 28, 1568-1577.

[12] Motegi, A. and Ohyama, K. (2005) Characteristics of Sleep Patterns and Lifestyle in Young Children. The Journal of Child Health, 64, 39-45. (In Japanese)

[13] Ehrenkranz, R.A., Younes, N., Lemons, J.A., Fanaroff, A.A., Donovan, E.F., Wright, L.L., et al. (1999) Longitudinal Growth of Hospitalized Very Low Birth Weight Infants. Pediatrics, 104, 280-289.

[14] Cooke, R.J. (2010) Postnatal Growth and Development in the Preterm and Small for Gestational Age Infant. Nestle Nutrition Institute Workshop, Pediatric Program, 65, 85-95. http://dx.doi.org/10.1159/000281149 